\title{
Two different pathways of phosphatidylcholine synthesis, the Kennedy Pathway and the Lands Cycle, differentially regulate cellular triacylglycerol storage
}

\author{
Christine Moessinger ${ }^{1,3 \dagger}$, Kristina Klizaite $^{1 \dagger}$, Almut Steinhagen ${ }^{1}$, Julia Philippou-Massier ${ }^{1,3}$, Andrej Shevchenko ${ }^{3}$, \\ Michael Hoch ${ }^{1}$, Christer S Ejsing ${ }^{2}$ and Christoph Thiele ${ }^{1^{*}}$
}

\begin{abstract}
Background: Lipids are stored within cells in lipid droplets (LDs). They consist of a core of neutral lipids surrounded by a monolayer of phospholipids, predominantly phosphatidylcholine (PC). LDs are very dynamic and can rapidly change in size upon lipid uptake or release. These dynamics require a fast adaptation of LD surface. We have recently shown that two Lands cycle PC synthesizing enyzmes, LPCAT1 and LPCAT2 can localize to the LD surface.

Results: Here, we show that knock-down of both enzymes leads to an increase in LD size without changes in the total amount of neutral lipids, while interference with the de-novo Kennedy pathway PC biosynthesis is associated with changes in triacylglyceride synthesis. We show that function of LPCAT1 and 2 is conserved in Drosophila melanogaster by the ortholog CG32699. Furthermore we demonstrate that modulation of the LD pool by LPCAT1 influences the release of lipoprotein from liver cells.

Conclusion: Activity of the Kennedy pathway regulates the balance between phospholipids and neutral lipids, while the Lands cycle regulates lipid droplet size by regulating surface availability and influencing surface to volume ratio. Differences in lipid droplet size may account for differences in lipid dynamics and be relevant to understand lipid overload diseases.
\end{abstract}

Keywords: Lysophosphatidylcholine, Acyl transferase, Lipid droplets, Drosophila melanogaster

\section{Background}

Lipids are important components of cells, with a function in cellular structure, regulation, signaling and as energy source, in particular neutral lipids. The cellular location of storage of neutral lipid is the lipid droplet (LD). LDs consist of a core of neutral lipids that is surrounded by a monolayer of phospholipids, mainly phosphatidylcholine [1-3]. Different proteins are associated with the LDs, including several enzymes of lipid metabolism [4-15].

Many metabolic disorders like diabetes and cardiovascular diseases are associated with defects in lipid

\footnotetext{
* Correspondence: cthiele@uni-bonn.de

${ }^{\dagger}$ Equal contributors

'Life and Medical Sciences Institute, University of Bonn, Carl-Troll-Str. 31

53115 Bonn, Germany

Full list of author information is available at the end of the article
}

metabolism and derive from additive defects in different pathways, often described as metabolic syndrome that can gradually progress into more severe diseases. The first step is usually the excess storage of lipids within different body tissues resulting in the development of obesity [16-19]. Therefore, it is crucial to understand how the storage of lipids is regulated under normal conditions.

Lipids are in a constant flux and are continuously converted into each other. Within cells they can move within membranes and between different cellular compartments. Furthermore, lipids are exchanged between different tissues. Extracellularly, the bulk of lipids is transported in lipoproteins. These lipoproteins are soluble complexes of proteins (apolipoproteins) and lipids that are transported in the circulation of vertebrates and insects and that are synthesized in the liver and intestine. They are classified 
into chylomicrons $(\mathrm{CM})$, very low density (VLDL), low density (LDL) and high density (HDL) lipoproteins based on their apolipoprotein component and their density, which is determined by the lipid composition [20]. The major neutral lipid, triacylglycerol (TAG), is secreted from the liver and intestine in apolipoprotein B (apoB) containing lipoproteins ( $\mathrm{CM}$ and VLDL). In contrast to other apolipoproteins, apoB is not exchangeable between lipoproteins and resides in the plasma in a lipid-associated form only. While VLDL and CM contain apoE, apoC and apoB, LDL harbors exclusively apoB. In the absence of loaded lipids apoB cannot be secreted and is rapidly degraded [21,22]. The TAG secreted as CM and VLDL mainly derives from TAG stored in cytosolic LDs [23].

Depending on cell type, nutritional status and developmental state the LD pool can vary in droplet number, size and localization within short time scales [24]. The growth of LDs and the incorporation of FAs into TAG is a fast event, typically taking just a few minutes $[25,26]$. Once formed, lipid droplets can fuse with each other [27] or transfer material by a slow coalescence event [28-30]. Chronic stimulation of lipolysis in adipocytes results in a fragmentation of large LDs into small LDs, which are dispersed throughout the cell [4,31-33]. These rapid changes of the LD core require a similarly rapid increase or decrease of the LD surface or an adaptation of the surface to volume ratio.

The major phospholipid of the LD surface, phosphatidylcholine, can be synthesized by three different pathways: the de-novo pathway, which is also known as Kennedy pathway, the Lands cycle and the phosphatidylethanolamine methyl transferase (PEMT) pathway, which is restricted to liver cells [34]. In the Kennedy pathway, phosphocholine is activated with cytidine triphosphate (CTP) and transferred to diacylglyceride (DAG) to form PC. These reactions are catalyzed by the cytoplasmic CTP:phosphocholine cytidylyltransferase (CT alpha) and the membrane-embedded cholinephosphotransferase or choline/ethanolamine phosphotransferase (CEPT1/CPT1) [35]. In the Lands cycle phospholipase A2 (PLA2) removes fatty acids at the $s n-2$ position of $\mathrm{PC}$, which results in the formation of lysophosphatidylcholine (LPC). This can be used in a reverse reaction, the addition of a fatty acid at the sn- 2 position, to yield PC. This re-acylation is catalyzed by lysophosphatidylcholine acyltransferases (LPCATs) [36]. Recently, four LPCATs were cloned and characterized [37-42]. They are all reported to localize to the ER compartment. Due to their structure they divide into two subgroups with LPCAT1 and LPCAT2 in one and LPCAT3 and LPCAT4 in the other group. LPCAT1 is reported to function in lung surfactant production, while LPCAT2 seems to be important in inflammatory reactions.

We have recently shown that diacylglycerol acyltransferase 2 (DGAT2) can localize to the surface of LDs and is active in synthesizing locally TAG stored in the core of LDs [25]. Furthermore, we have also shown that two enzymes of the Lands cycle, LPCAT1 and LPCAT2, can localize to the surface of LDs and that they can synthesize PC directly at the LD [43].

Here, we show that these proteins are important for the morphology of the cellular LD pool in different mammalian cell types and Drosophila melanogaster. We demonstrate that interference with both cellular PC synthesis pathways results in an increase in LD size, but due to different mechanisms. We identified the LPCAT $1 / 2$ ortholog in Drosophila melanogaster and demonstrate its LPCAT activity. Additionally, we show that interference with LPCAT1 influences lipoprotein particle secretion from hepatoma cells.

\section{Results}

Knockdown of LPCAT1 and LPCAT2 increases LD size

Since both LPCAT1 and LPCAT2 are present and active at the surface of LDs, we investigated their importance for the cellular LD pool. If local production of PC by LPCAT1 and LPCAT2 is functionally important for the LD monolayer, manipulation of LPCAT activity may result in a phenotypic alteration of cellular LD pools. Therefore, we performed siRNA-mediated gene silencing of the LPCATs followed by microscopic imaging of LDs, quantification of LD size and number and further characterization of the phenotype. A double knockdown (KD) of LPCAT1 and LPCAT2 by means of two different specific siRNAs targeting LPCAT1 and LPCAT2 lead to a reduction of both proteins in A431 cells (Figure 1A). This reduction resulted in a significant increase in the mean size of LDs, expressed as the cross-sectional area (Figure $1 \mathrm{~B}$ and $\mathrm{C}$ ) and a slightly reduced number of LDs (Figure 1D). Since double KDs are difficult and phenotypes are weak due to mutual compensation by the isoenzymes, we also analyzed the human hepatoma cell line $\mathrm{HuH7}$, which expresses LPCAT3 [41] and LPCAT1, but no LPCAT2 [43]. Knockdown of LPCAT1 in HuH7 cells with two different siRNA sequences resulted in a decreased LPCAT activity in whole cell lysates (Figure 2A, upper row) and in a decrease in LPCAT1 protein down to about $10 \%$ of control (Figure 2A, middle row). Phenotypically, this $\mathrm{KD}$ resulted in the appearance of larger LDs (Figure 2B). A quantification of the microscopic images revealed a significant increase in the mean LD size upon LPCAT1 KD (Figure 2C). This increase is due to a shift in the LD size distribution from small LDs $\left(50-300 \mathrm{~nm}^{2}\right)$ to larger LDs $\left(400 \mathrm{~nm}^{2}->1 \mu \mathrm{m}^{2}\right)$ (Figure 2D). This increase in size is paralleled by a significant decrease in number of LDs (Figure 2E). The results show that a reduction of LPCAT1 and LPCAT2 leads to a shift of the cellular LD sizes to larger LDs accompanied by simultaneous decrease in number of LDs in different cell types. 


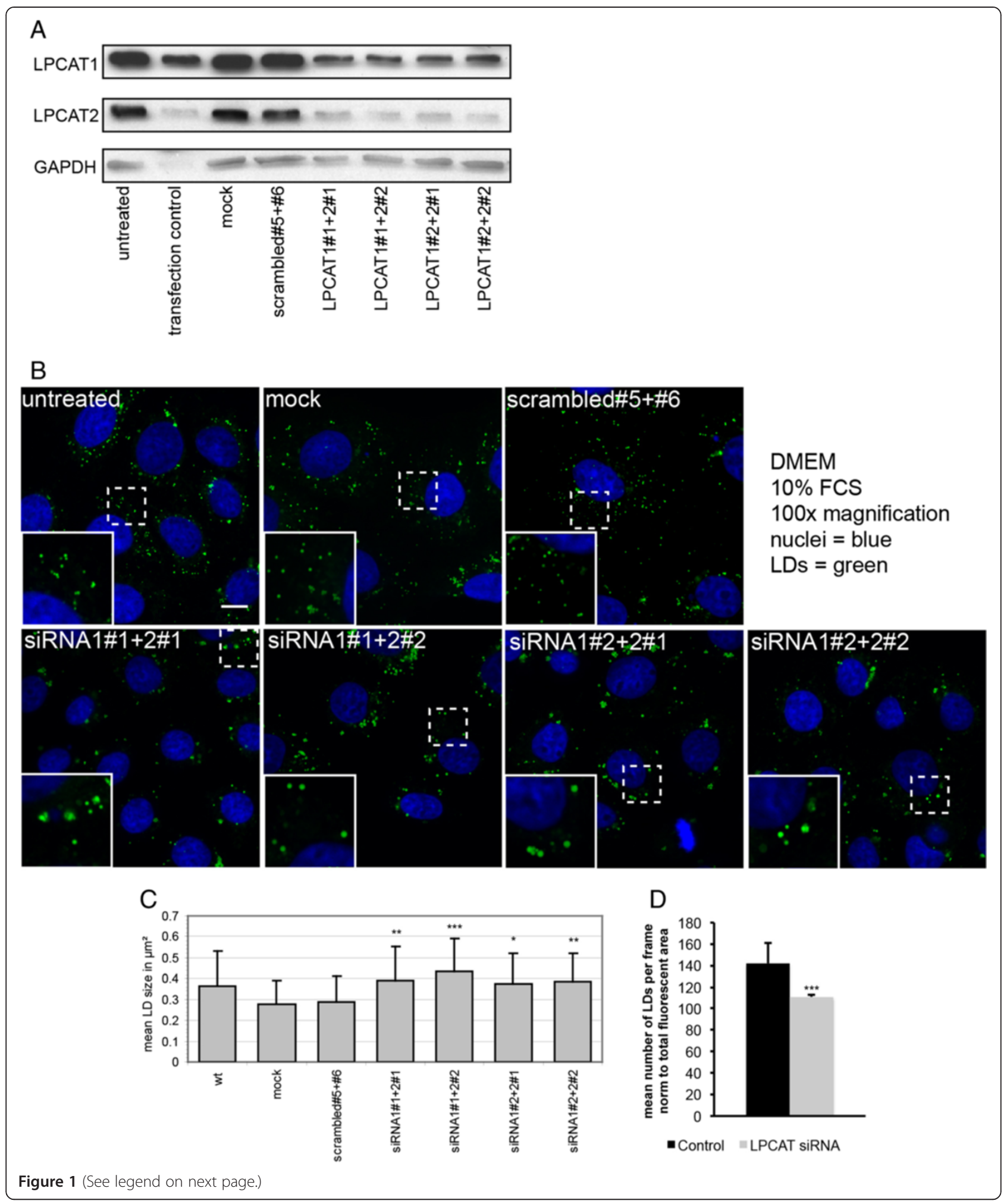


(See figure on previous page.)

Figure 1 Silencing of LPCAT1 and LPCAT2 by siRNA leads to enlarged lipid droplets in A431 cells. A) A431 cells were either left untreated (untreated, wt), mock transfected (mock), transfected with control siRNA (eg5 as transfection control, leads to cell death, or scrambled\#5+\#6 as non-targeting siRNAs) or the four possible combinations of two sequences each against LPCAT1 or LPCAT2 as indicated. After $48 \mathrm{~h}$ cells were lysed and subjected to SDS-PAGE/Western blotting for LPCAT1, LPCAT2 and glycerol-3-phosphate dehydrogenase (GAPDH, as a load control). B) Confocal images of controls and LPCAT1/LPCAT2 double-knock-downs as described in panel A. Nuclei (blue), LDs (green), scalebar = $10 \mu \mathrm{m}$. C) Confocal images as described in panel $\mathbf{B}$ were quantified with Image J for LD size distribution as described in Methods. Data are mean LD size \pm StdDev, calculated from $>50$ individual cells in 3 independent experiments. Significances relative to non-targeting siRNAs were calculated by unpaired two-sided $T$-test analysis (*** $p \leq 0.001,{ }^{* *} p \leq 0.01,{ }^{*} p \leq 0.05$ ). D) Confocal image as described in panel $\mathbf{B}$ were quantified with ImageJ. Data show mean lipid droplet number per frame, corrected for variations in cell density, calculated from $>50$ individual cells in 3 independent experiments. Control: scrambled\#5 + \#6, LPCAT siRNA: average of all siRNA treatments. Significance was calculated by unpaired two-sided T-test analysis (*** $\mathrm{p} \leq 0.001)$.

\section{Knock-down of LPCAT1 in HuH7 cells reduces lipoprotein particle secretion}

$\mathrm{HuH7}$ cells synthesize and secrete apoB containing VLDL particles [21,44] with a similar density as LDL particles (Additional file 1: Figure S1), whose assembly requires the long-chain acyl-CoA synthetase ACSL3 [45]. This protein activates fatty acids for subsequent incorporation into PC and localizes to LDs [46], suggesting that it functions together with LPCAT1 in PC synthesis at LDs. Earlier studies suggested that secretion of VLDL would depend on mobilization of TAG from LDs [23], which might be slower when small LDs are replaced by larger LDs with a smaller surface to volume ratio. Given these close connections between hepatic TAG and PC metabolism, we hypothesized that LPCAT1 activity might also influence lipoprotein assembly and secretion. To address this issue, we monitored the secretion of lipoprotein particles from $\mathrm{HuH} 7$ cells by measuring the amount of secreted apolipoprotein B (apoB). Knockdown of LPCAT1 with two distinct siRNAs resulted in a significant reduction of apoB secretion and a decrease in secretion of radiolabeled lipids (Figure 2F).

\section{LD size increase occurs without changes in the neutral lipid pool}

An increase of LD size can result from an overall increased storage of neutral lipids, particularly TAG, or from a morphological rearrangement of the LD pool at constant TAG amounts. Neither A431 (Figure 3A) nor $\mathrm{HuH7}$ (Figure 3C) cells showed a difference in incorporation of alkyne-labeled oleate into TAG relative to incorporation into PC between control siRNA-treated cells and cells treated with LPCAT1- and LPCAT2-specific siRNA. Additionally, also the amount of other major lipid species remained unchanged independent of the siRNA treatment in both cell lines, A431 (Figure 3B) and HuH7 (Figure 3D). The results suggest that the mechanism for the increase in LD size results from an adjustment of the surface to volume ratio rather than the formation of more neutral lipids.
LD size increase by inhibition of the de-novo PC synthesis pathway is connected to changes in neutral lipid content It was reported that interference with the de-novo PC pathway also results in increased LD size in S2 cells $[47,48]$. Furthermore, the inhibition of this pathway leads to a switch in lipid metabolism from the formation of PC towards the formation of TAG [49]. In A431 cells, we observed an increase in the size of LDs (Figure 4A,B) upon knockdown of CTalpha mRNA (Figure 4C) along with a decrease of the ratio of PC to TAG biosynthesis (Figure 4D). Steady state lipid pool size, analyzed by mass spectrometry, showed a non-significant tendency towards increased TAG and $\mathrm{CE}$ and a significant reduction of ether-linked PC (Figure 4E) upon CTalpha knock-down.

LPCAT3 and LPCAT4 do not influence the cellular LD pool Besides the homologous LPCAT1 and LPCAT2 two other proteins with LPCAT activity were identified and named LPCAT3 and LPCAT4 [41,50]. These proteins belong to a different family of proteins and are multispan transmembrane proteins structurally related to ACAT (Acyl-CoA Cholesterol Acyltransferase) proteins. Especially, the ubiquitous LPCAT3 was reported to be the main LPCAT in liver cells [41]. Though these proteins were not identified on LDs, but were reported to localize to the ER compartment, we investigated whether a single or double knockdown of these proteins has an effect on the LD pool. In A431 cells, no effect on the mean LD size (Figure 5A) was observed upon knock-down of LPCAT3 mRNA, LPCAT4 mRNA or combinations thereof (Figure 5B) Consistent with the fact that neither LPCAT3 nor LPCAT4 localize to LDs, LPCAT activities of LD preparations were unaffected by the knock-downs (Figure 5C), while total cell lysates showed significantly reduced LPCAT activities (Figure 5D). This indicates that only LPCATs with the ability to localize to LDs influence the LD size.

The Drosophila melanogaster LPCAT1/2 ortholog CG32699 has LPCAT activity, localizes to LDs and regulates LD size The ability to form LDs is conserved from yeast to mammals, and orthologs of many mammalian LD proteins and 

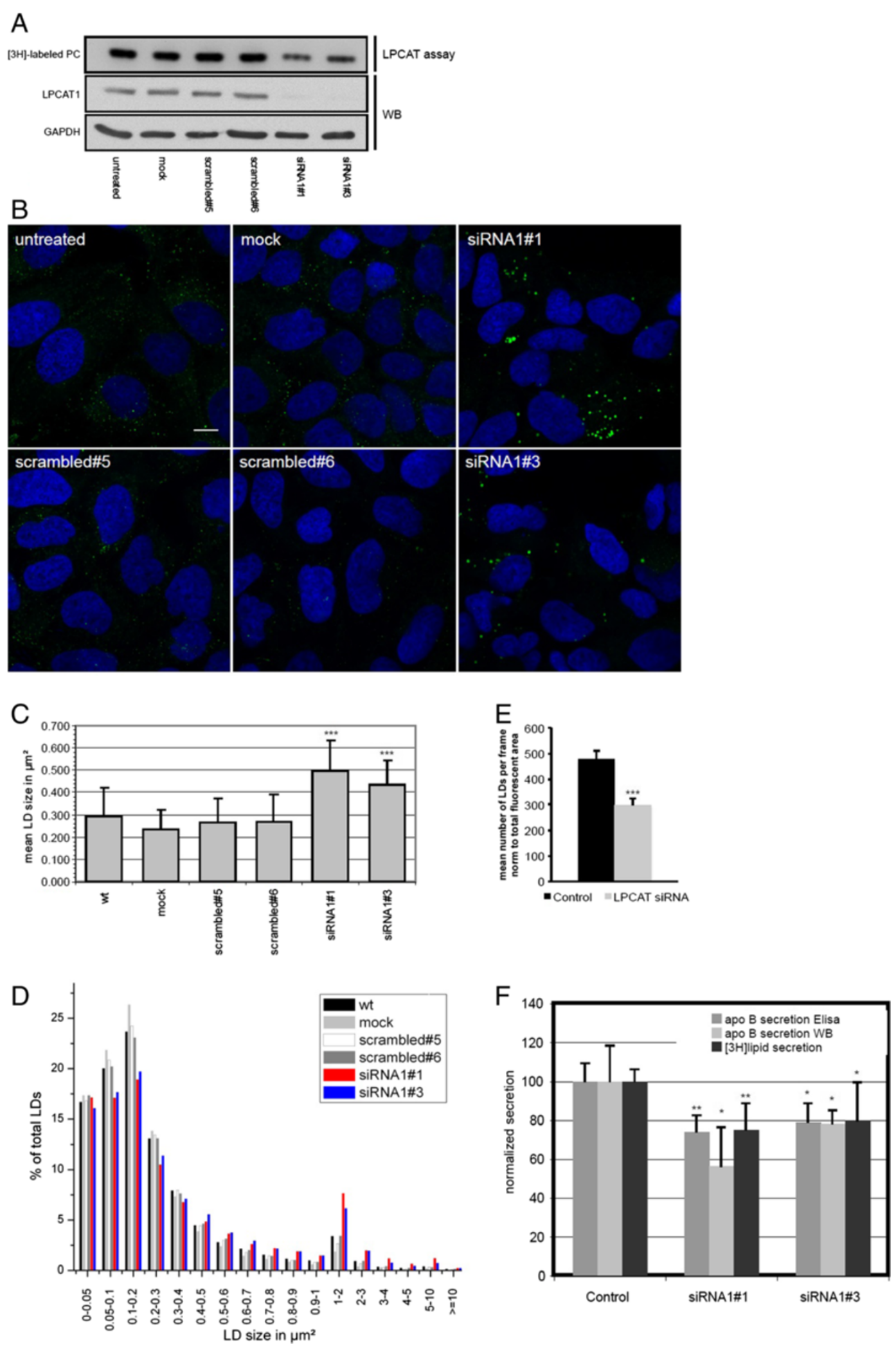

Figure $\mathbf{2}$ (See legend on next page.) 
(See figure on previous page.)

Figure 2 Silencing of LPCAT1 by siRNA leads to enlarged lipid droplets and reduced lipoprotein secretion in HuH7 cells. A) HuH7 cells were either left untreated (untreated, wt), mock transfected (mock), transfected with control siRNA (scrambled\#5 or scrambled\#6 as non-targeting siRNAs) or the two different siRNA sequences against LPCAT1 as indicated. After $72 \mathrm{~h}$ cells were subjected to a LPCAT activity assay or Western blotting (WB) for LPCAT1 using GAPDH, as load control. B) Confocal images of controls and LPCAT1 knock-downs as described in panel A. Nuclei (blue), LDs (green), scale bar = $10 \mu \mathrm{m} \mathbf{C}+\mathbf{D}$ ) Confocal images as described in panel $\mathbf{B}$ were quantified for LD size distribution as described in Methods. Data represented mean LD size \pm StdDev, calculated from > 50 individual cells in 3 independent experiments. Significances were calculated by unpaired two-sided T-test analysis relative to non-targeting siRNA (scrambled\#5) (*** $p \leq 0.001$ ). For analysis of LD size distribution (panel $\mathbf{D})$, LDs were grouped into size classes, and the distribution displayed as percentage of total LDs per size class. Controls (black, light and dark grey and white), siRNAs against LPCAT1 (red, blue). E) Confocal images as described in panel B were quantified with Image J. Data show mean lipid droplet number per frame, corrected for variations in cell density, calculated from $>50$ individual cells in 3 independent experiments. Control: average of scrambled\#5 and scrambled\#6, LPCAT siRNA: average of both siRNA treatments. Significance was calculated by unpaired two-sided T-test analysis (*** $p \leq 0.001)$. F) HuH7 cells were transfected with non-targeting siRNA (control) or different siRNA sequences targeting LPCAT1 as indicated. ApoB secretion was measured by ELISA (dark grey, data represent mean \pm StdDev, $n=4$ ) or by Western blotting (light grey, data represent mean \pm StdDev, $n=5$ ). [3H]lipid secretion after labeling with $1 \mu \mathrm{Ci}[3 \mathrm{H}]$ oleate was calculated as \% of total radioactivity recovered (supernatant + cells) and normalized to control. Data represent mean \pm StdDev, $n=4$. $p$-Values were obtained by unpaired T-test relative to the respective control $\left(* * 0 \leq 0.01,{ }^{*} p \leq 0.05\right)$.

enzymes involved in lipid metabolism are reported in model organisms like Drosophila melanogaster [47,51-54]. In Drosophila, cutting-edge genetic technologies can be combined with immunohistochemistry, cell biology and biochemistry approaches. Furthermore, manipulations of the metabolism can be achieved by feeding specific diets that contain particular metabolites (e.g. labeled lipids) or chemical inhibitors [55-57] and the analysis of metabolite/ lipid fluxes between tissues can be studied. Many functions of the mammalian liver and adipose tissue are executed in the insects fat body, an organ that is particularly pronounced in the late larval state [58].

In order to test whether the influence of the LD localizing LPCAT1 and LPCAT2 on the cellular LD pool is conserved in evolution, we investigated their function on the organismic level. LPCAT1 and LPCAT2 have one predicted ortholog in Drosophila melanogaster, which is annotated as CG32699 and is predicted to be a LPC acyltransferase. GFP-conjugated CG32699 in oleatesupplemented S2 cells showed colocalization with LDs (Figure 6A). Three different CG32699-specific RNAi Drosophila strains showed reduced levels of CG32699 mRNA (Figure 6B, inset). By DIC microscopy on isolated fat bodies of L3 larvae, we observed enlarged LDs in the fat body of RNAi strains (Figure 6B). Quantification of DIC images from RNAi strains show a reduction in the number of LDs (Figure 6C) while the size of LDs is increased (Figure 6D), similar as was seen for mammalian cells in culture. LPCAT activity assays on L3 larvae showed that LPCAT activity was decreased in the RNAi strains, indicating that this protein indeed has LPCAT activity (Figure 6E). These results show that the influence of LPCAT1/2 on the cellular LD pool is a general property of these proteins beyond cell types and species.

\section{Discussion}

To rationalize the different effects of the above knockdowns, it is necessary to recapitulate the different isoenzymes and pathways that produce the main components of LDs, i.e. TAG and PC. In most eukaryotes, TAG is produced by DGAT1 and DGAT2. While DGAT1 is a multispan protein localizing to the ER [59], DGAT2 has a hairpin structure and localizes to both the ER and LDs $[25,60,61]$. A similar, but more complex situation exists for the synthesis of PC. The formation of CDP-choline by $\mathrm{CT}$ alpha, the rate limiting step of the $\mathrm{PC}$ de-novo Kennedy pathway, localizes to LDs and ER [15], but the actual synthesis of PC by CEPT1 and CPT1 is confined to the ER and Golgi [62] and not found on LDs [43]. The alternative LPCAT pathway, which forms PC from LPC and acyl-CoA (Lands cycle), has at least four isoenzymes, two of which, i.e. LPCAT3/4, are exclusively on the ER $[41,63]$, while LPCAT1/2 again localize to ER and LDs $[43,64]$. Direct regulatory interactions between the pathways exist, e.g. LPCAT1 promotes the ubiquitinmediated degradation of CPT1 [65]. Analogous to DGAT1, LPCAT3/4 are multispan proteins [41,63] while LPCAT1/2 have a hairpin structure like DGAT2 [43]. Some tissues, particularly liver, and organisms such as bakers yeast have in addition the PEMT pathway to convert PE to PC by methylation [66], which will not be discussed in more detail here.

Essentially, our data now show that reduction of LPCAT $1 / 2$ results in unchanged balance between PC and TAG synthesis, along with a remodeling of LD morphology towards larger LDs, while reduction of the de novo pathway enzyme $\mathrm{CT}$ alpha changes the balance between PC and TAG synthesis towards the latter, accompanied by larger LDs and higher TAG content. Reduction of ER-localized LPCAT3/4 apparently does not influence neutral lipid storage. Also, knockdown of LPCAT1 decreases lipoprotein secretion by hepatoma cells.

These observations are consistent with the following scenario: De-novo PC synthesis by the Kennedy pathway occurs mostly at the ER and depends on the availability of choline and its activation to CDP-choline by CT alpha. 

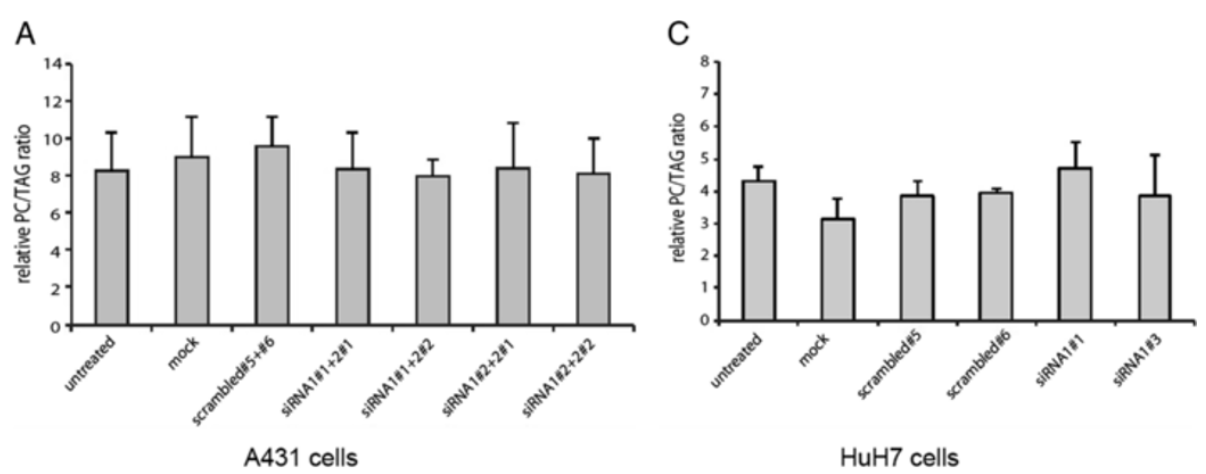

B
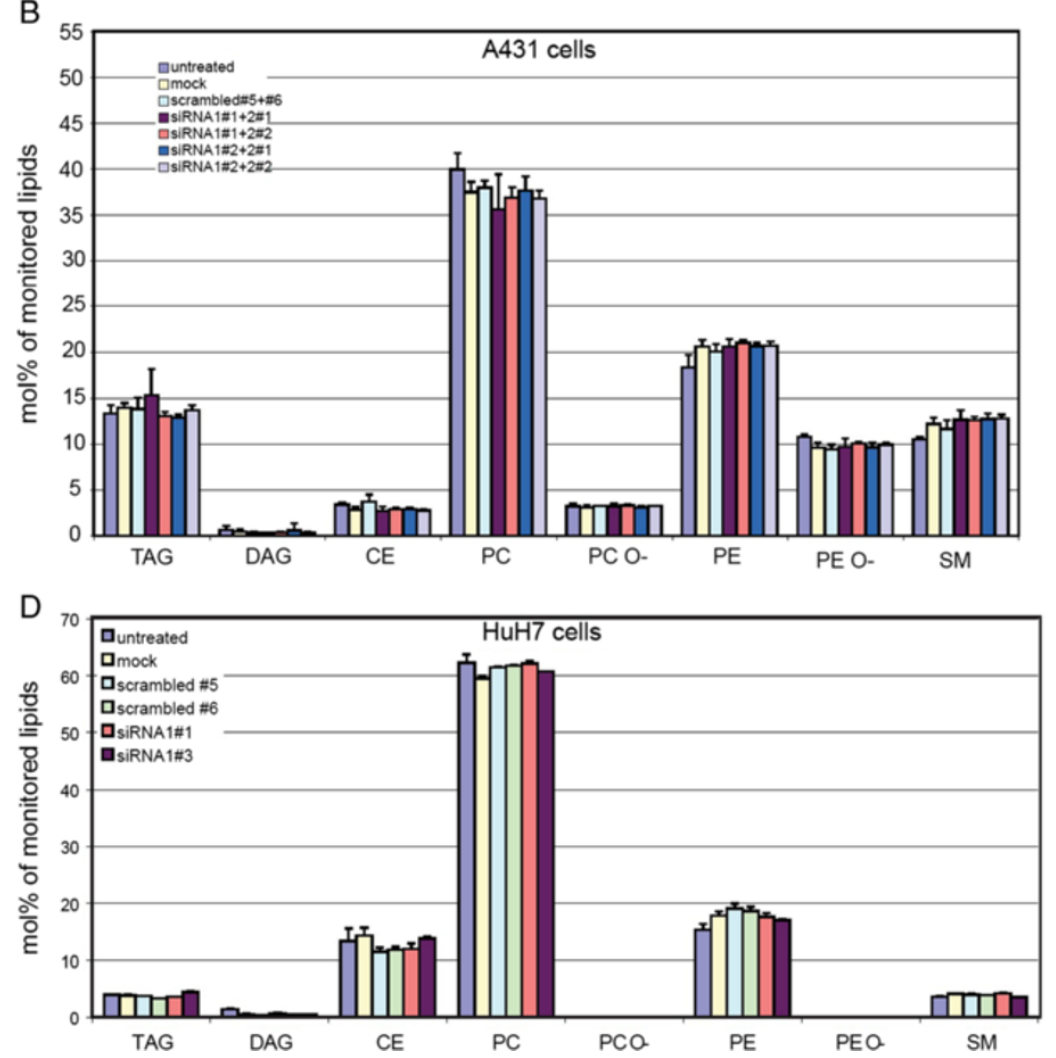

Figure 3 Increase in LD size upon LPCAT1/2 knock-down is independent of neutral lipid synthesis and accumulation. A) A431 cells were transfected with siRNA as described in Figure 1A. Seventy hours after siRNA transfection growth medium was exchanged to medium containing $10 \%$ delipidated FCS and $50 \mu \mathrm{M}$ alkyne-oleate. After two hours cells were washed and lipids extracted. Extracts were subjected to quantitative click-analysis for the ratio of incorporation of alkyne fatty acid into TAG and PC. Data are mean \pm StdDev, $n=3$. Significances were calculated by unpaired two-sided T-test analysis relative to non-targeting siRNA (scrambled\#5 + \#6) and were found to be insignificant. B) A431 cells were transfected as described in Figure 1A. After $48 \mathrm{~h}$, total lipid extracts were analyzed by mass spectrometry in duplicate samples, and species abundances were normalized to the corresponding internal standard. The molar contents of each species of the same class were summed up and normalized to the total content of all detectable lipids. C) HuH7 cells were transfected with siRNA as described in Figure 2A. Seventy hours after siRNA transfection as indicated, growth medium was exchanged to medium containing 10\% delipidated FCS and $50 \mu \mathrm{M}$ alkyne-oleate. After two hours, cells were washed, lipids extracted and extracts were subjected to quantitative click-analysis as in panel A. Data are mean \pm StdDev, $\mathrm{n}=3$. Significances were calculated compared to non-targeting siRNAs (scrambled\#5) and were found to be insignificant. D) HuH7 cells were transfected as described in Figure 2A. After $72 \mathrm{~h}$, total lipid extracts were analyzed by mass spectrometry in duplicate samples. Species abundances were normalized as described for panel $\mathbf{B}$.

If other precursors and metabolic energy are available but choline is lacking, low PC synthesis capacity is balanced by increased synthesis and storage of neutral lipid [67]. The small extra amount of LD surface PC that is necessary to store the increased amounts of TAG [68] is likely recruited from other cellular membranes. Since cell growth and division requires synthesis of PC [69,70], the stored TAG can provide the precursors for PC synthesis once 

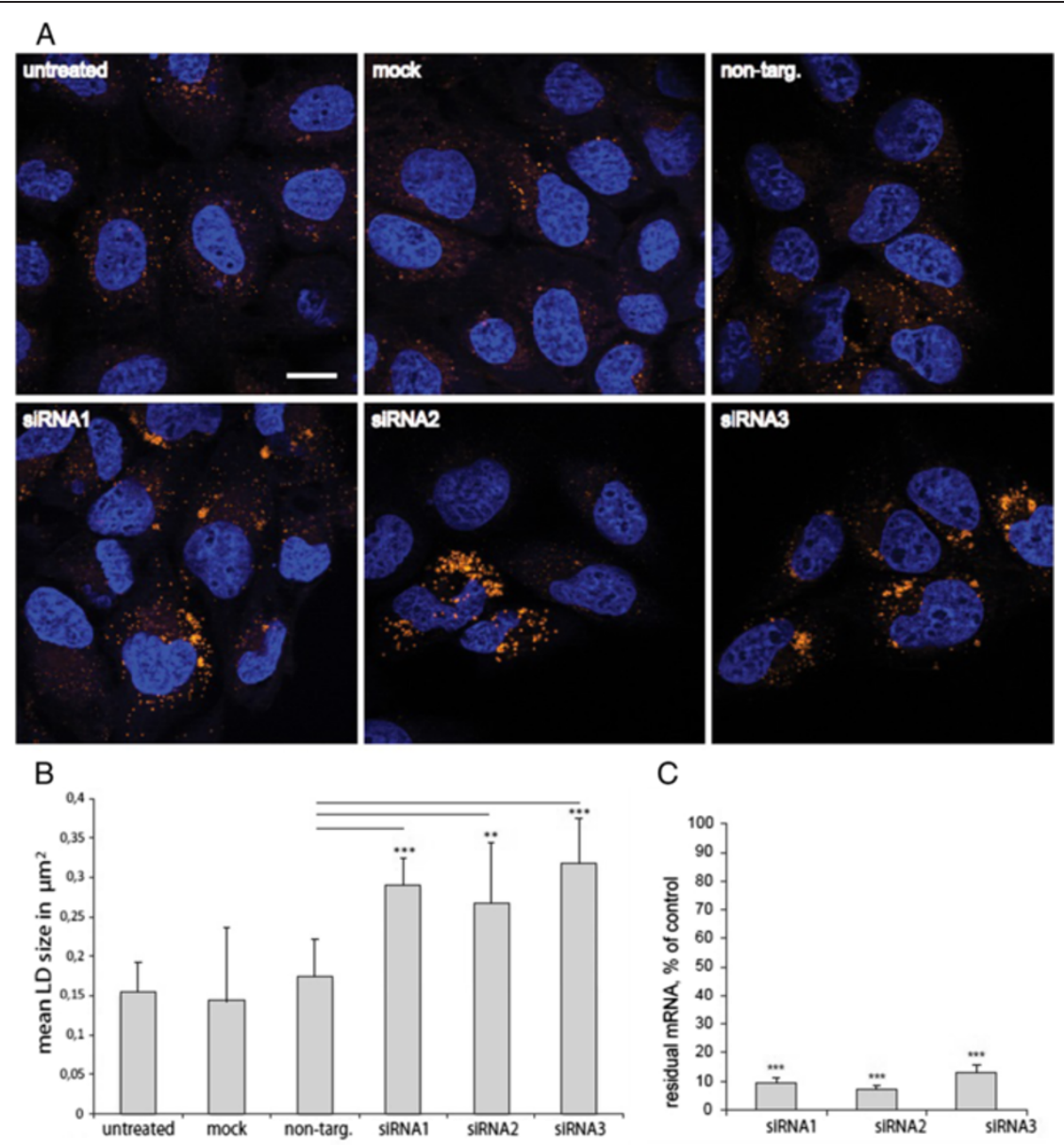

C
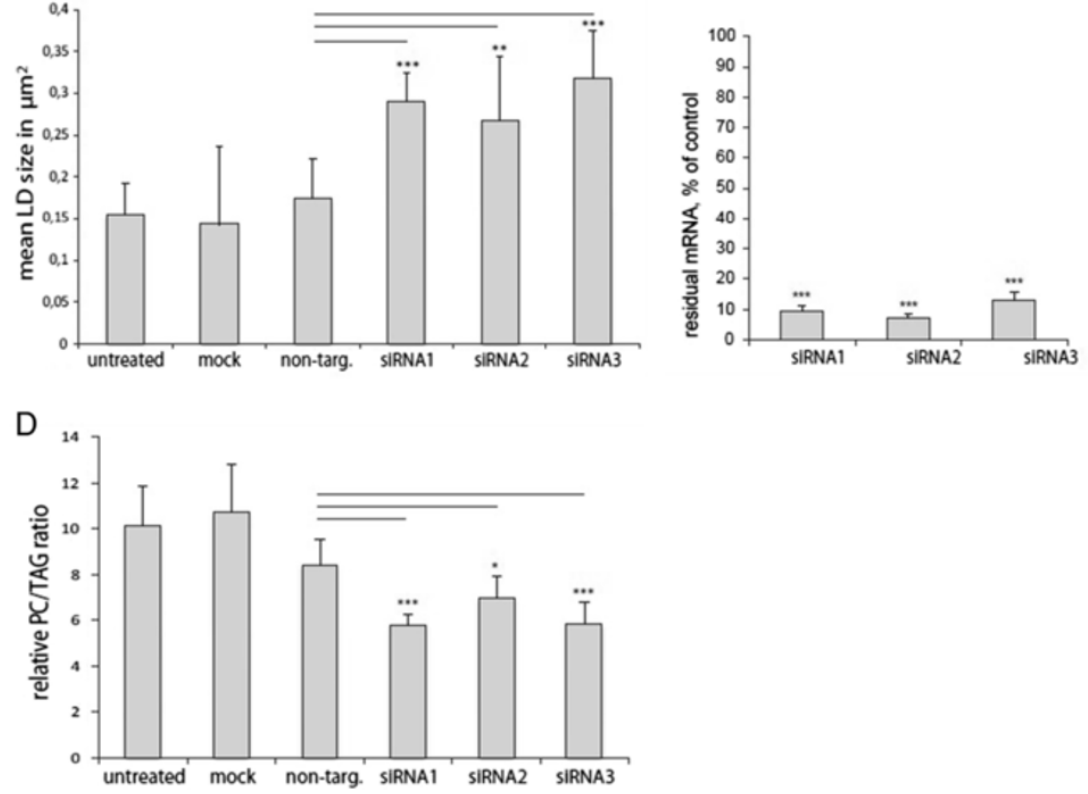

E

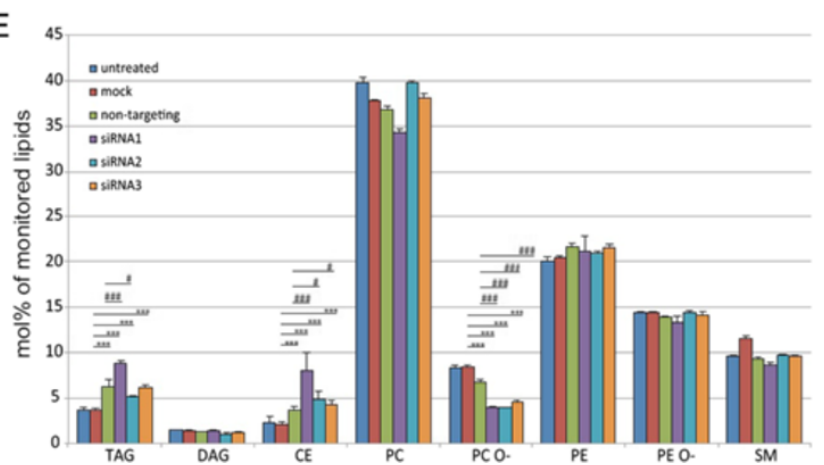

Figure 4 (See legend on next page.) 


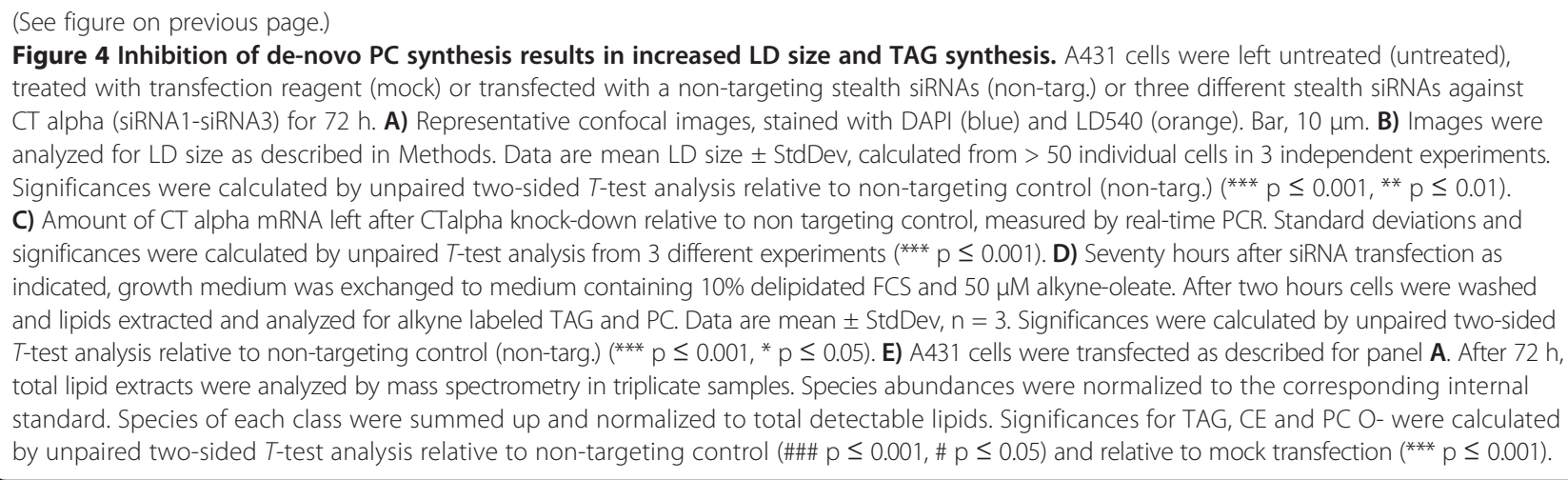

CDP-choline becomes available. In this situation, the rapid synthesis of PC is supported by the activation of CT alpha upon recruitment to LDs (64). The de-novo synthetic PC will be processed by the Lands cycle enzymes LPCAT1-4. Amongst those, LPCAT1/2 influence the LD size but not the amount of synthesized PC or TAG. The increase of LD size upon decrease of LPCAT1/2 activity suggests that these enzymes are either involved in the recruitment of PC to the growing LDs by vectorial acylation of the soluble precursor LPC or that their effect on PC species composition reduces the tendency of LDs to coalesce. The fact that reduction of LPCAT3/4 does not result in the same phenotype underlines the importance of compartmentalization. The different physical properties of bilayer and monolayer membranes lead to separation of these isoenzymes with polytopic and monotopic mode of membranes insertion. This allows compartmentalization of synthesis and maintenance of separate pools with different fate, but makes cells susceptible towards defects in one of the enzymes.

The complex organization of lipid metabolism is also illustrated by the role of LPCAT activity in lipoprotein secretion. Knockdown of LPCAT1 reduced lipoprotein secretion but had a very small effect on cellular lipid composition (Figure 3D). Previous findings suggested that lipidation of VLDL requires breakdown of stored TAG and transfer of released fatty acids from LDs to VLDL [23] possibly via ER-luminal LDs [71]. Therefore, it is possible that LPCAT1 influences lipid secretion by direct supply of PC for the formation of lipoprotein particles in the ER, although it appears unlikely that reduced LPCAT1 leads to a shortage of PC at the ER, where the PC de-novo synthesis pathway operates. Reduced VLDL secretion in $\mathrm{HuH7}$ cells was also observed upon knock-down of ACSL3, and could be rescued by supplementation with PC [45]. Since both ACSL3 [46] and LPCAT1 localize to LDs, this supports the idea that ACSL3 supplies acyl-CoAs to LPCAT1 to generate PC on the LD surface, where about $50 \%$ of cellular LPCAT1 are found in HuH7 cells. The influence on lipid secretion may then arise from a changed lipid mobilization from LDs, where an increase in LD surface seems to be connected to increased lipolysis [31-33]. It is possible that the activity of LPCAT1 is needed to provide surface area for the LD attachment of lipid degrading and transferring proteins. By this way interference with LPCAT1 would slow down lipid secretion without interfering with the actual secretion process.

The phenotype of LPCAT1/2 depletion is identical in both, cultured cells and in the fat body of the multicellular organism Drosophila melanogaster. Since it is reported that many mammalian proteins and signalling pathways in lipid metabolism are conserved in Drosophila melanogaster (Brummer-ATGL, CG1882-CGI-58, CG11055HSL, LSDs-PAT) [72] the similar phenotype in the mammalian cell lines and Drosophila fat body suggest a conserved mechanisms of LD surface control. As this single ortholog behaves similar to the mammalian proteins, it will be easier accessible for functional studies. In particular with the Drosophila model there is a multicellular model available, in which the importance of the protein in development or in lipid fluxes between tissues can be studied by creating a real knock-out fly.

\section{Conclusion}

LDs are dynamic organelles that grow or shrink within minutes during periods of high FA availability or upon stimulation of lipolysis. We showed that for the growth of LDs the necessary enzymatic activities, namely DGAT2 for TAG production and LPCAT1 and LPCAT2 for surface PC production, are directly located to the surface of the LD. In line with the idea of local adjustment of LDs to growth and shrinkage, we showed that reduction of surface PC producing enzymes LPCAT1 and LPCAT2 influences lipid packaging. The restriction of LD PC synthesizing enzymes leads to increased LD size paralleled by reduced LD number, unchanged cellular neutral lipid content and reduced cellular lipid release. Our observations also emphasize the importance of isoenzymes, their different cellular localization and parallel synthesis pathways. 


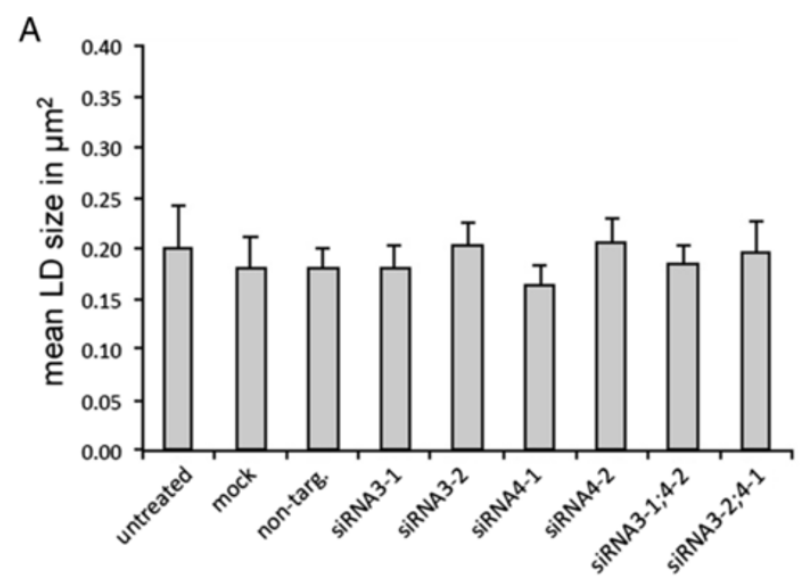

B

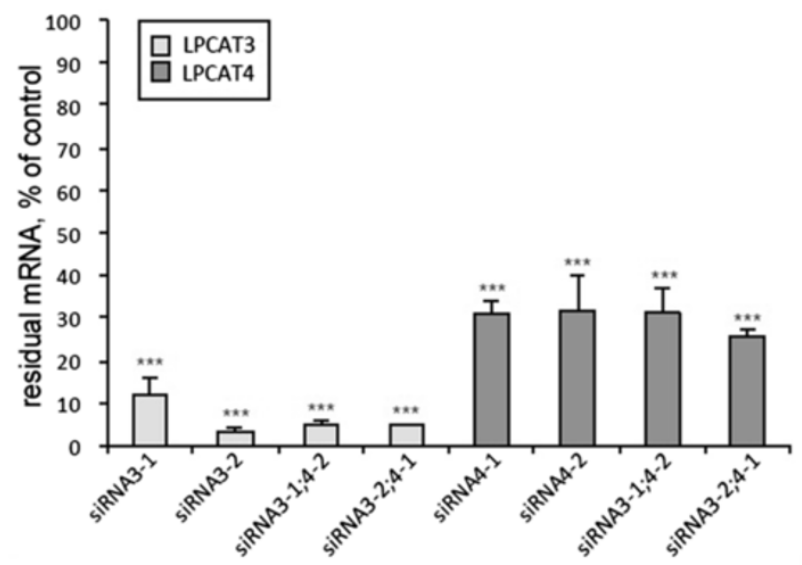

C

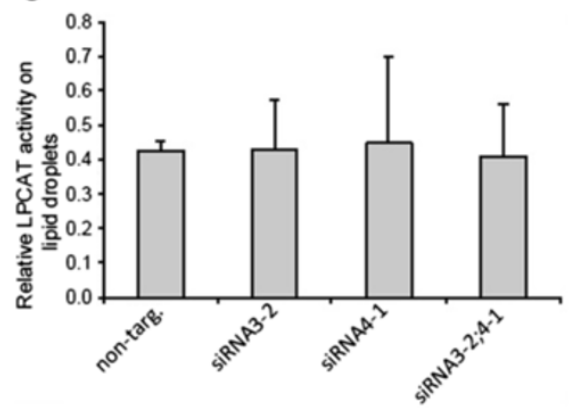

D

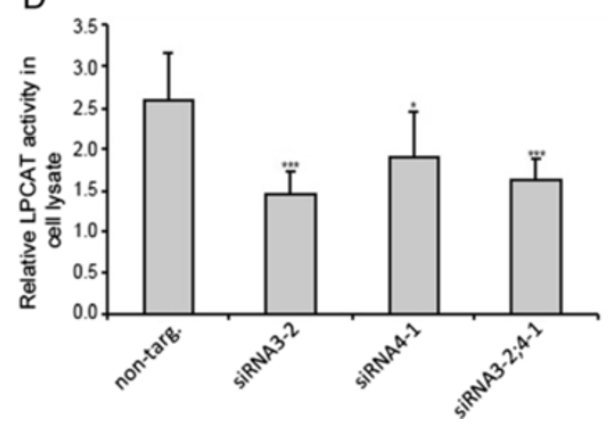

Figure $\mathbf{5}$ LD size is unaffected by knock-down of LPCAT3 and LPCAT4. A) A431 cells were either left untreated, mock transfected (mock) or transfected with a non-targeting stealth siRNAs (non-targ.) or with the two different stealth siRNA sequences against LPCAT3 (siRNA3-1, siRNA3-2) or LPCAT4 (siRNA4-1, siRNA4-2) or combinations thereof as indicated. After $72 \mathrm{~h}$ incubation cells were fixed, stained with DAPI and LD540 and imaged. LD size was quantified with ImageJ. Standard deviations and significances were calculated from 3 experiments by unpaired T-test analysis compared to non-targeting control and were found to be insignificant. B) mRNA was measured by real-time PCR after single or double knock-down of LPCAT3 and LPCAT4 as described for panel A. Values are shown relative to the non-targeting control. Standard deviations and significances were calculated as above $\left(* * * 0 \leq 0.001,{ }^{* *} p \leq 0.01\right)$. C) A431 cells were either transfected with non-targeting stealth siRNA or with stealth siRNA sequence against LPCAT3 (siRNA3-2) or LPCAT4 (siRNA4-1) or combination (siRNA3-2;4-1). $48 \mathrm{~h}$ after transfection $100 \mu \mathrm{M}$ oleate was added to the medium to induce formation of LDs. $72 \mathrm{~h}$ after transfection cells were lysed and lipid droplets were purified using sucrose gradient and subjected to a LPCAT activity assay. Values are normalized to the amount of the LD protein NSDHL as determined by western blotting. Standard deviations and significances were calculated as above and were found to be insignificant. D) A431 cells were treated with stealth siRNA and supplemented with oleate as described for panel C. $72 \mathrm{~h}$ after transfection cells were lysed and lysate was subjected to a LPCAT activity assay using equal amounts of total protein. Standard deviations and significances were calculated from three experiments as above $(* * * \leq 0.001$, * $p \leq 0.05)$ compared to non-targeting control. 


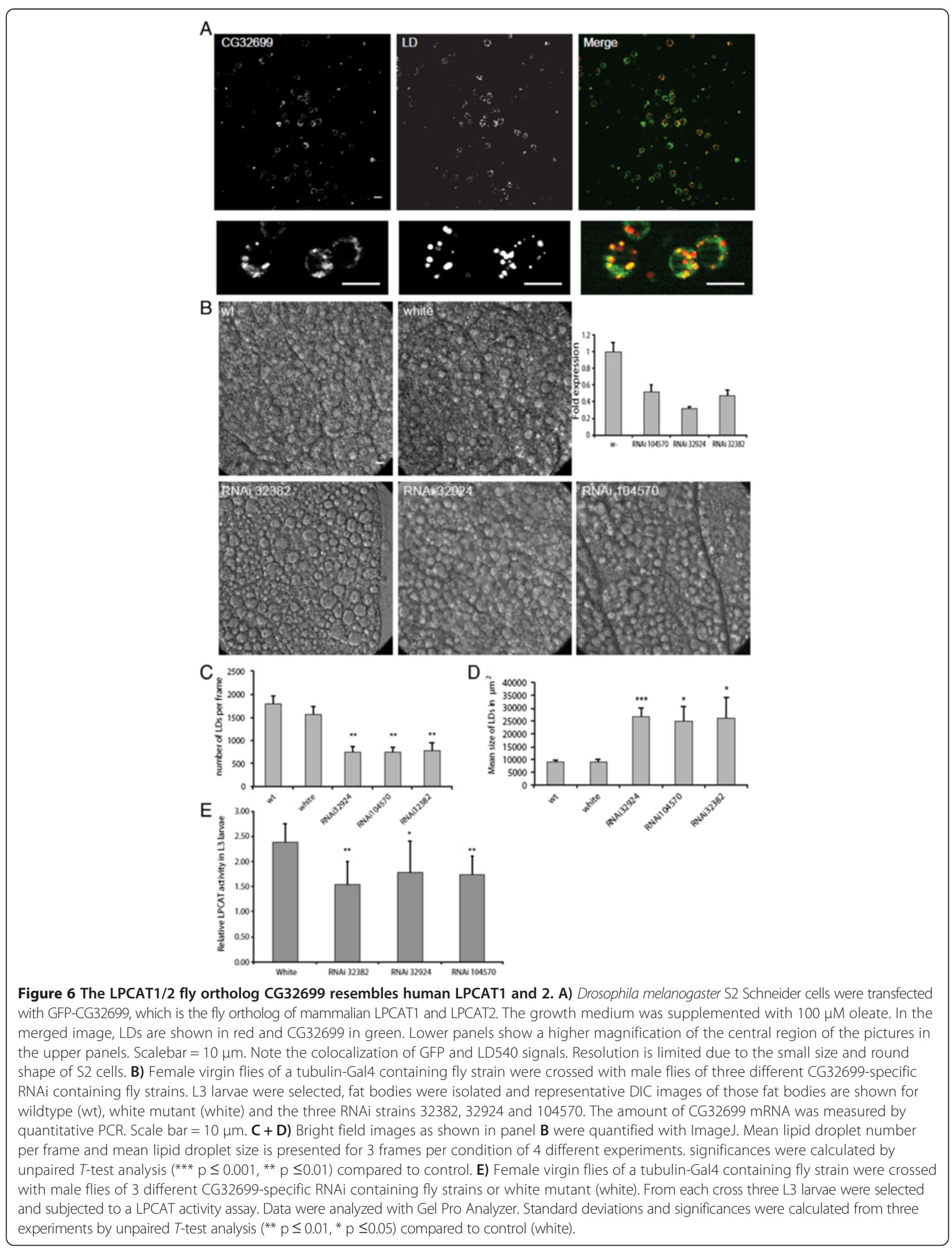


We showed that only LPCAT1 and LPCAT2, which localize to the ER and LDs, are able to influence the LD pool while the isoenzymes LPCAT3 and LPCAT4, which localize to the ER, had no effect on the LD pool. Furthermore, we showed that interference with de-novo PC synthesis pathway also influences the LD pool leading to a similar phenotype as interference with the Land cycle, but due to a different mechanism. While interference with de-novo PC synthesis stimulates TAG synthesis and LD loading, interference of the Lands cycle PC synthesis influences lipid packing by reduction of available or appropriate surface. Our study identified an LPCAT1/2 ortholog in Drosophila melanogaster with similar function in regulating the cellular LD pool, emphasizing the generality and conservation of the underlying regulatory network. Our work stresses the need to understand the differences and importance of parallel synthesis pathways, isoenzymes and localization of reactions in order to understand physiological and pathological lipid storage.

\section{Methods \\ Antibodies}

Polyclonal rabbit antisera against the C-terminal peptide of human LPCAT1 CNSDAGRKPVRKKLD, conjugated to keyhole limpet hemocyanin, and against purified recombinant 6 His-hLPCAT2 $310-545$ were raised by Eurogentec (Seraing, Belgium) and were affinity purified against the respective antigen. Polyclonal goat anti-apoB was from Merck Bioscience, monoclonal mouse anti-GAPDH antibody was from Novus Biological, HRP-coupled polyclonal rabbit anti-goatIgG antibody from Invitrogen and HRPcoupled polyclonal goat anti-rabbitlgG and anti-mouselgG from Dianova.

\section{siRNA sequences}

siRNA sequences against LPCAT1-4 were from Ambion with the following order IDs:

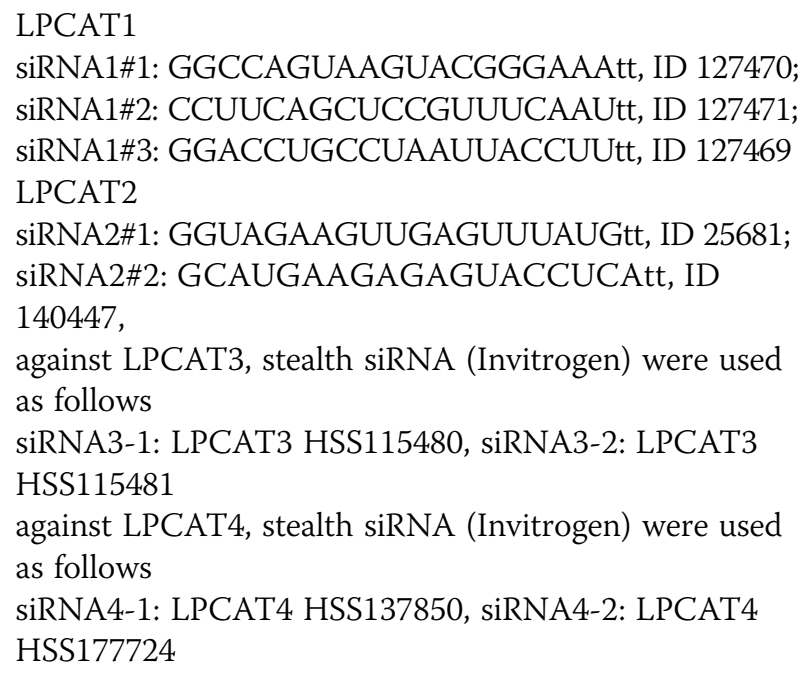

against CT1alpha, stealth siRNA (Invitrogen) were used as follows

siRNA1: PCYT1A HSS107689, siRNA2: PCYT1A

HSS107690, siRNA3: PCYT1A HSS107691.

\section{Drosophila strains}

Control strains Oregon- $\mathrm{R}$ and $\mathrm{w}^{1118}$ were from Bloomington Stock Center, the Gal4 driver strain tubulin-Gal4/ TM3 was a gift of the Eaton Lab at MPI-CBG. UASCG32699RNAi strains (v32382, v32924 and v104570) were obtained from the Vienna Drosophila RNAi Center.

\section{Kits, reagents and chemicals}

QiaShredder and RNeasy Mini Prep Kit was from Qiagen, human apoB ELISA ${ }^{\text {PRO }}$ was from Mabtech (Nacka Strand, Sweden), RNase-free DNase was from Roche, reverse transcriptase and RNasin were from Promega, real-time PCR Lightcycler Mix and universal probes were from Roche, primers were synthesized by Biospring, Interferin was from Peqlab, $[3 \mathrm{H}]$ oleate was from Hartmann Analytic, the dyes 4',6-Diamidino-2-phenylindol (DAPI) was from Sigma-Aldrich and LD540 was synthesized as described in Spandl et al. [73].

\section{Cell culture}

A431 cells were maintained in Dulbeccos Modified Eagles Medium (DMEM, Gibco 31966) supplemented with 10\% fetal calf serum (FCS), HuH7 cells in RPMI (Gibco 31870) supplemented with $10 \mathrm{mM}$ HEPES, $0.1 \mathrm{mM}$ non-essential amino acids, $2 \mathrm{mM}$ L-Glutamine and 10\% FCS. Cells were grown at $37^{\circ} \mathrm{C}$ and $5 \% \mathrm{CO}_{2}$.

Unless specifically indicated, media were not supplemented with additional fatty acid.

\section{Drosophila Schneider 2 (S2) cells}

Schneider 2 (S2) cells were cultured in Schneider medium (PAN-Biotech) supplemented with 10\% FCS. Cells were grown in incubator at $28^{\circ} \mathrm{C}$. Transfection of S2 cells The fly gene CG32699 was cloned into a UAS-EGFP (kindly provided by Bernard Fuss) containing plasmid by using Xho1 and XbaI restriction enzymes, yielding a C-terminal eGFP tagged CG32699 protein. Expression was induced by cotransfection with pMT-Gal4, which is induced by $\mathrm{CuSO}_{4}$. Cells were transfected in serum-free S2 medium and Cellfectin (Invitrogen) with $2 \mu \mathrm{g}$ of each plasmid according to the manufacturers instructions. After $6 \mathrm{~h}$ serum-containing S2 medium was added. About $24 \mathrm{~h}$ after transfection the medium was replaced by serumcontaining S2 medium with $500 \mu \mathrm{M} \mathrm{CuSO}$. Cells were processed for immunofluorescence after $24 \mathrm{~h}$.

\section{siRNA transfection}

For transfection with siRNA, cells were seeded in 24well dishes at 5000 cells per well or 800000 per $15 \mathrm{~cm}$ 
dish and treated with Ambion siRNA (9 $\mathrm{nM}$ ) or stealth siRNA using Interferin or Lipofectamine 2000 (for stealth siRNA) according to the manufacturers instructions. After $48 \mathrm{~h}$ or $72 \mathrm{~h}$ cells were subjected to immunofluorescence, lipid analysis, RNA isolation or SDSPage/Western blotting.

\section{Fluorescence microscopy}

Cells were grown on glass coverslips and transfected with siRNA as indicated. After $48 \mathrm{~h}$ or $72 \mathrm{~h}$, cells were fixed with $3 \%(\mathrm{w} / \mathrm{v})$ of paraformaldehyde in PBS for $30 \mathrm{~min}$, washed with PBS and stained with DAPI and Bodipy $493 / 503$ or LD540 in PBS, followed by three washes in PBS. After rinsing in water, coverslips were mounted in Mowiol 4-88 containing 2.5\% 1,4-diazabicyclo[2.2.2] octane. Images were acquired with a Zeiss LSM 510 confocal microscope equipped with a $100 \times$ NA 1.3 oil objective using laser excitation at 364 and $488 \mathrm{~nm}$ or a ZEISS Axio Observer.Z1 with a $63 \times$ NA 1.2 objective.

\section{Quantification of fluorescent images}

Quantification was done with ImageJ particle analysis of the LD detecting channel. The threshold was set to omit the background, circularity adjusted to omit clusters and particle detection only at a size between 0,02 and $20 \mu \mathrm{m}^{2}$. The number of particles was normalized to the total fluorescent area detected in the frame LD staining channel.

\section{Purification of lipid droplets and LPCAT activity assay}

Cells were grown in $15 \mathrm{~cm}$ dishes and were supplemented with $100 \mu \mathrm{M}$ oleate $24 \mathrm{~h}$ before lipid droplet isolation. Cells were washed and scraped in ice-cold disruption buffer (20 mM Hepes/NaOH, pH 7.4, $0.25 \mathrm{M}$ sucrose, Roche Complete protease inhibitors) and homogenized using the EMBL cell-cracker (HGM) with 12 strokes using a maximum clearance of $18 \mu \mathrm{m}$. The lysate was centrifuged at $1000 \mathrm{~g}$ for $10 \mathrm{~min}$ and post-nuclear supernatant (PNS) was adjusted to $1.1 \mathrm{M}$ sucrose. Two $\mathrm{ml}$ of adjusted PNS were overlaid with $10 \mathrm{ml}$ of ice-cold disruption buffer in centrifuge tube. The gradients were centrifuged using a Beckman L-60 ultracentrifuge with the SW41 rotor at $110000 \mathrm{~g}$ at $4^{\circ} \mathrm{C}$ for $3 \mathrm{~h} .1 .5 \mathrm{ml}$ of lipid droplet fraction was collected from the top. For LPCAT activity assay $10 \mu \mathrm{l}$ of lysate (adjusted according to protein concentration measured with Bradford reagent) or $150 \mu \mathrm{l}$ of lipid droplet fraction (adjusted according to relative amount of NSDHL measured by WB analysis) were mixed with 100 or $150 \mu \mathrm{l}$ of assay buffer (200 mM Tris/ $\mathrm{HCl} \mathrm{pH} \mathrm{7.5,} 10 \mathrm{mM} \mathrm{MgCl}_{2}, 2 \mathrm{mg} / \mathrm{ml}$ fatty acid free BSA) supplemented with $100 \mu \mathrm{M}$ propargyl LPC (final concentration) and $20 \mu \mathrm{M}$ oleoyl-CoA (final concentration), and subsequently incubated for $10 \mathrm{~min}$ at $30^{\circ} \mathrm{C}$. Reaction was stopped by adding $800 \mu \mathrm{l}$ of chloroform/methanol, 1:3, and $400-600 \mu \mathrm{M}$ of $1 \%$ acetic acid in water. The phases were separated by centrifugation at $14000 \times \mathrm{g}$ for $30 \mathrm{~s}$. The chloroform phase was collected for the click reaction, which was performed as described below.

\section{Lipid extraction from 24 well plate}

Cells were washed twice with 1\% delipidated BSA in PBS and once with only PBS. Lipids were extracted directly from the dish using first $400 \mu \mathrm{l}$ of chloroform/methanol, 1:5 followed by $400 \mu \mathrm{l}$ of chloroform/methanol $1 / 1$. After addition of $600 \mu \mathrm{l}$ of water, phases were separated by centrifugation. The chloroform phase was collected for Click reaction, which was performed as described below.

\section{Lipid analysis by mass spectrometry}

Cell were scraped into $155 \mathrm{mM} \mathrm{NH} \mathrm{NCO}_{3}$ and were mixed with $20 \mu \mathrm{l}$ internal lipid standard mixture providing a spike of 57 pmol PE 17:0/17:0, 47 pmol PC 18:3/ 18:3, 47 pmol SM 17:0, 37 pmol DAG 17:0/17:0, 37 pmol TAG 17:1/17:1/17:1 and 57 pmol CE 17:0. Samples were extracted with $990 \mu \mathrm{l}$ chloroform/methanol (15:1) for $120 \mathrm{~min}$ at $4^{\circ} \mathrm{C}$ [74]. The apolar organic phase was isolated and evaporated. Lipid extracts were dissolved in $200 \mu \mathrm{l}$ of $7.5 \mathrm{mM}$ ammonium acetate in chloroform/ methanol/2-propanol (1:2:4) and subjected to quantitative lipid analysis in positive ion mode on a QSTAR Pulsar- $i$ instrument (MDS Analytical Technologies) or a LTQ Orbitrap mass spectrometer (Thermo Fisher Scientific) equipped with a TriVersa NanoMate nanoflow ion source (Advion Biosciences, Inc., Ithaca, NJ) [74-77].

\section{Real-time PCR}

RNA was extracted into $30 \mu \mathrm{l}$ nuclease-free water from a 24-well according to manufactures description with the RNeasy Mini Prep Kit (Qiagen). RNA $(11 \mu \mathrm{l})$ was transcribed to cDNA using reverse Transcriptase. The cDNA was diluted 1:5 with nuclease-free water and $4 \mu \mathrm{l}$ were used for real-time PCR. Real-time PCR was performed on a LightCycler 480 II from Roche using the universal probe system from Roche. For LPCAT3 Sonde8, for LPCAT4 Sonde48, for CTalpha Sonde 72 and as reference gene GAPDH Sonde60 were used. Sequences of the RT-PCR Primer: LPCAT3 Primer1: GGGCTACGTCTCCTTCG ATT, Primer2: ATTTGTCCCACGTGAAGAGG; LPCAT4 Primer1: GCGTTGGAACCACAGCTC, Primer2: ACATA GCCAGCGGACAGC; CTalpha Primer1: GATGAGGTG GTGAGGAATGC, Primer2: TGCCAGCAGATGAATA AGGA; GAPDH Primer1: AGCCACATCGCTCAGACAC; Primer2: GCCCAATACGACCAAATCC.

Real-time PCR analysis of Drosophila strains was performed as described in [57]. RpL32 (rp49) Primer 1: GCTAAGCTGTCGCACAAATG, Primer2:GTTCGATC 
CGTAACCGATG;CG32699 Primer1: GGATGATCTCA AAGCGAAACC, Primer2: CCTTCATGGTCACATAG TGGA.

\section{Analysis of Drosophila melanogaster strains}

Four to six L3 larvae were collected and dissected in PBS on ice. Fat bodies were transferred in PBS to object slides on ice and covered with coverslips. Microscopy was performed with a $63 \times$ NA 1.2 water objective using differential interference contrast brightfield. The images were processed and analysed with ImageJ. Processing of the image includes sharpening, despeckle and contrast enhancement. Structures were detect with the functions Find Edges, Make Binary, Morphology Tool (circle 5.00, close), Binary erode, Set Threshold, and analyse particle (circle, micron ${ }^{2}, 0$-infinity, exclude edges). The number and size of particles detected were selected as output data. The analysis is based on 4 independent experiments and 3 pictures per condition per experiment. The significance was calculated by unpaired students $T$-Test to wildtype fly larvae.

\section{Acyltransferase assay in L3 larvae using click chemistry}

We applied the assay procedure as recently described [78], based on quantitative click-analysis of lipid metabolism [79]. L3 larvae were homogenized with a pestle and $60 \mu \mathrm{l}$ of disruption buffer $(20 \mathrm{mM}$ HEPES/NaOH, $\mathrm{pH}$ 7.4, $0.25 \mathrm{M}$ sucrose) was added. Then it was mixed with $40 \mu \mathrm{l}$ of assay buffer $(150 \mathrm{mM}$ Tris/ $\mathrm{HCl}, \mathrm{pH} 7.5$, $7.5 \mathrm{mM} \mathrm{MgCl}, 1.5 \mathrm{mg} / \mathrm{ml}$ fatty acid-free bovine serum albumin (BSA), $250 \mu \mathrm{M}$ oleoyl-CoA (Sigma), $250 \mu \mathrm{M}$ propargyl LPC) and $10 \mathrm{~min}$ incubation at $30^{\circ} \mathrm{C}$ followed. Reaction was stopped by adding $500 \mu \mathrm{l}$ of chloroform/ methanol, 1:3, and $500 \mu \mathrm{l}$ of $1 \%$ acetic acid in water. The phases were separated by centrifugation at $1900 \times \mathrm{g}$ for $5 \mathrm{~min}$. The upper phase was removed and $70 \mu \mathrm{l}$ of the lower chloroform phase was taken for Click reaction. Chloroform was evaporated, then $7 \mu \mathrm{l}$ of chloroform and $30 \mu \mathrm{l}$ of reaction mixture $\left(2.3 \mathrm{mM} \mathrm{Cu}(\mathrm{I}) \mathrm{BF}_{4}\right.$, $0.08 \mathrm{mM}$ hydroxyazidocoumarin in ethanol/acetonitrile, 3.4:1) was added and $2.5 \mathrm{~h}$ incubation at $42^{\circ} \mathrm{C}$ followed. Reaction mixture was separated by TLC, first in $\mathrm{CHCl}_{3} / \mathrm{MeOH} / \mathrm{H}_{2} \mathrm{O} /$ Acetic acid, 65:25:4:1 for $40 \mathrm{~min}$, then in hexane/ethyl acetate, 1:1 for $30 \mathrm{~min}$. The plate was dried, briefly immersed into $4 \%$ diisopropylethylamine in hexane, dried again and exposed to $420 \mathrm{~nm}$ light. Emission signal was detected with CCD camera and then quantified.

\section{ApoB secretion assays}

$\mathrm{HuH} 7$ cells were plated in 24well plates (5000 cells per well) $16 \mathrm{~h}$ prior transfection. Cells were transfected with siRNAs (control siRNA scrambled\#5 or \#6 and siRNA against LPCAT1 siRNA1\#1 and siRNA1\#3) using the transfection reagent Interferin according to manufactures instructions. Transfections were performed in $100 \mu \mathrm{l} \mathrm{OPTI-MEM}$ and $500 \mu \mathrm{l}$ serum-free supplemented RPMI medium. In case of radioactive quantification of lipid release, $1 \mu \mathrm{Ci}[3 \mathrm{H}]$ oleate was added to the medium per 24-well for $24 \mathrm{~h}$. Then, remaining radioactivity was removed and cells were grown in $200 \mu \mathrm{l}$ serum-free supplemented RPMI for further $48 \mathrm{~h}$. In case of apoB determination by apoB ELISA, siRNAs were removed after $24 \mathrm{~h}$ and cells were grown for further $48 \mathrm{~h}$ in $200 \mu \mathrm{l}$ serum-free RPMI. Supernatants were collected $72 \mathrm{~h}$ after transfection and corresponding cells were either scraped in $50 \mu \mathrm{l}$ Lämmli buffer (apoB measurement by Western blotting) or lipids were extracted (measurement of radioactive labeled lipid release) or protein content was measured with a protein detection assay from Bio-Rad (apoB measurement by ELISA). Supernatants were either mixed with Lämmli buffer (apoB measurement by Western blotting) or lipids were extracted (measurement of radioactive labeled lipid release) or they were subjected to human apoB ELISA ${ }^{\text {PRO }}$ from Mabtech (Nacka Strand, Sweden). For quantification of apoB release by Western blotting, supernatant $(40 \mu \mathrm{l})$ and cell lysate $(15 \mu \mathrm{l})$ were subjected to SDS-PAGE and Western blotting and analyzed for apoB and LPCAT1 and GAPDH, respectively, and the amounts for apoB and LPCAT1 were normalized to GAPDH and compared to control. For characterization and quantification of released radiolabeled lipids, the extracted lipids were separated by thin layer chromatography or quantifed by scintillation counting. For quantifaction of apoB release by ELISA the amount of apoB released was normalized to the total protein content and compared to control.

\section{Additional file}

Additional file 1: Figure S1. Density profile of apolipoprotein B containing lipoprotein particles secreted from $\mathrm{HuH7}$ cells. Supernatant of $\mathrm{HuH7}$ cells was separated by density gradient centrifugation based on sodium chloride and sodium bromide containing medium and the different density fractions were blotted for apoB protein.

\section{Abbreviations \\ apoB: apolipoprotein B; CM: Chylomicron; CT: CTP:phosphocholine cytidylyltransferase; CPT: Cholinephosphotransferase; DAG: Diacylglyceride; FA: Fatty acid; HDL: High-density lipoprotein particle; KD: Knock-down; LD: Lipid droplet; LDL: Low-density lipoprotein particle; LPC: Lysophophatidylcholine; LPCAT: Lysophosphatidylcholine acyltransferase; PC: Phosphatidylcholine; TAG: Triacylglyceride; VLDL: Very low-density lipoprotein particle.}

\section{Competing interests}

The authors declare that they have no competing interests.

\section{Authors' contributions}

CM designed the study, performed experiments, analysed data and drafted the manuscript, KK preformed experiments, analysed data and helped to draft the manuscript, ASt characterized Drosophila strains by qPCR, JP-M 
established the siRNA knock-down strategy for the study, ASh designed and interpreted the mass spectrometry data, $\mathrm{MH}$ helped to draft the manuscript, CE carried out the mass spectrometric analysis and drafted the manuscript, $\mathrm{CT}$ designed and supervised the study, analysed data and drafted the manuscript. All authors read and approved the final manuscript.

\section{Authors' information}

CM did her PhD at the Max-Planck Institute of Cell Biology and Genetics in Dresden, Germany in the group of Christoph Thiele in the field of cellular lipid metabolism and lipid storage. She continued with this topic as a Postdoc at the LIMES Institute, University of Bonn, Germany. Currently, she is an EMBO financed postdoctoral fellow at the Karolinska Institute in Stockholm, Sweden in the field of transendothelial nutrient transport in physiological and diabetic settings and associated vascular complications. KK is a PhD student at the LIMES institute, University of Bonn, Germany in the group of Christoph Thiele in the field of lipid droplet biology and metabolism in cells and mouse model.

ASt is a PhD student at the LIMES institute, University of Bonn in the group of Michael Hoch working with the Drosophila melanogaster animal model to identifying new regulators and genetic networks controlling innate immunity, lipid metabolism and cell signaling.

JP-M did her PhD at the Max-Planck Institute for Cell Biology and Genetics in Dresden, Germany and a Postdoc at the LIMES Institute, University of Bonn. She has an expertise in siRNA and screen technology. Currently, she is establishing a robotic high-throughput facility at the Gene Center Munich ASh is research group leader and expert in mass spectrometric methods at the Max-Planck Institute for Cell Biology and Genetics in Dresden, Germany. $\mathrm{MH}$ is a professor and head of the LIMES institute, University of Bonn, Germany. His research is aiming to identify new key regulators and genetic networks, which control metabolism and cell and organ physiology and linking these network to immune system, aging and pathological metabolic conditions.

CE is associate professor at the University of Southern Denmark in Odense, Denmark. His research focuses on development and application of mass spectrometry-based lipidomics techniques.

$\mathrm{CT}$ is professor and head of the Membrane Biology and Biochemistry Unit in the Molecular Biomedicine Division at the LIMES Institute, University of Bonn, Germany. His research is focused on neutral lipid metabolism, lipid droplet biology and the development of new tools for lipid and protein detection.

\section{Acknowledgements}

We thank the MPI-CBG light microscopy facility for support of image acquisition. We thank the lab of Suzanne Eaton at MPI-CBG, Dresden, especially Wilhelm Palm, Falko Riedel, Marco Brankatsch, Helena Khaliullina-Skultety and the lab of Michael Hoch, University of Bonn, LIMES, especially Bernard Fuss for help with the Drosophila work and providing strains and pUAS-eGFP and pMT-Gal4 vector. We received funding from the DFG (Transregio TRR83, Teilprojekt 7, 12, 17), the EU Framework VII project "LipidomicNet", the German National Academic Foundation and the European Molecular Biology Organisation.

\section{Author details}

${ }^{1}$ Life and Medical Sciences Institute, University of Bonn, Carl-Troll-Str. 31, 53115 Bonn, Germany. 2 Department of Biochemistry and Molecular Biology, University of Southern Denmark, Campusvej 55, 5230 Odense, Denmark. ${ }^{3}$ Max Planck Institute of Molecular Cell Biology and Genetics,

Pfotenhauerstrasse 108, D-01307 Dresden, Germany.

Received: 19 February 2014 Accepted: 17 November 2014 Published online: 10 December 2014

\section{References}

1. Walther TC, Farese RV Jr: The life of lipid droplets. Biochim Biophys Acta 2009, 1791(6):459-466.

2. Bartz R, Li WH, Venables B, Zehmer JK, Roth MR, Welti R, Anderson RG, Liu P, Chapman KD: Lipidomics reveals that adiposomes store ether lipids and mediate phospholipid traffic. J Lipid Res 2007, 48(4):837-847.

3. Tauchi-Sato K, Ozeki S, Houjou T, Taguchi R, Fujimoto T: The surface of lipid droplets is a phospholipid monolayer with a unique Fatty Acid composition. J Biol Chem 2002, 277(46):44507-44512.
4. Brasaemle DL, Dolios G, Shapiro L, Wang R: Proteomic analysis of proteins associated with lipid droplets of basal and lipolytically stimulated 3 T3-L1 adipocytes. J Biol Chem 2004, 279(45):46835-46842.

5. Fujimoto Y, Itabe H, Sakai J, Makita M, Noda J, Mori M, Higashi Y, Kojima S, Takano T: Identification of major proteins in the lipid droplet-enriched fraction isolated from the human hepatocyte cell line HuH7. Biochim Biophys Acta 2004, 1644(1):47-59.

6. Liu P, Ying Y, Zhao Y, Mundy DI, Zhu M, Anderson RG: Chinese hamster ovary K2 cell lipid droplets appear to be metabolic organelles involved in membrane traffic. J Biol Chem 2004, 279(5):3787-3792.

7. Umlauf E, Csaszar E, Moertelmaier M, Schuetz GJ, Parton RG, Prohaska R: Association of stomatin with lipid bodies. J Biol Chem 2004, 279(22):23699-23709.

8. Ozeki S, Cheng J, Tauchi-Sato K, Hatano N, Taniguchi H, Fujimoto T: Rab18 localizes to lipid droplets and induces their close apposition to the endoplasmic reticulum-derived membrane. J Cell Sci 2005, 118(Pt 12):2601-2611.

9. Sato S, Fukasawa M, Yamakawa Y, Natsume T, Suzuki T, Shoji I, Aizaki H, Miyamura T, Nishijima M: Proteomic profiling of lipid droplet proteins in hepatoma cell lines expressing hepatitis $C$ virus core protein. J Biochem 2006, 139(5):921-930.

10. Turro S, Ingelmo-Torres M, Estanyol JM, Tebar F, Fernandez MA, Albor CV, Gaus K, Grewal T, Enrich C, Pol A: Identification and characterization of associated with lipid droplet protein 1: a novel membrane-associated protein that resides on hepatic lipid droplets. Traffic 2006, 7(9):1254-1269.

11. Bartz R, Zehmer JK, Zhu M, Chen Y, Serrero G, Zhao Y, Liu P: Dynamic activity of lipid droplets: protein phosphorylation and GTP-mediated protein translocation. J Proteome Res 2007, 6(8):3256-3265.

12. Cermelli S, Guo Y, Gross SP, Welte MA: The lipid-droplet proteome reveals that droplets are a protein-storage depot. Curr Biol 2006, 16(18):1783-1795.

13. Beller M, Riedel D, Jansch L, Dieterich G, Wehland J, Jackle H, Kuhnlein RP: Characterization of the Drosophila lipid droplet subproteome. Mol Cell Proteomics 2006, 5(6):1082-1094.

14. Athenstaedt K, Zweytick D, Jandrositz A, Kohlwein SD, Daum G: Identification and characterization of major lipid particle proteins of the yeast Saccharomyces cerevisiae. J Bacteriol 1999, 181(20):6441-6448.

15. Krahmer N, Hilger M, Kory N, Wilfling F, Stoehr G, Mann M, Farese RV Jr, Walther TC: Protein correlation profiles identify lipid droplet proteins with high confidence. Mol Cell Proteomics 2013, 12(5):1115-1126.

16. Jeffcoat R: Obesity - a perspective based on the biochemical interrelationship of lipids and carbohydrates. Med Hypotheses 2007, 68(5):1159-1171.

17. Gesta S, Tseng YH, Kahn CR: Developmental origin of fat: tracking obesity to its source. Cell 2007, 131(2):242-256.

18. Le Lay S, Dugail I: Connecting lipid droplet biology and the metabolic syndrome. Prog Lipid Res 2009, 48(3-4):191-195.

19. Unger RH, Clark GO, Scherer PE, Orci L: Lipid homeostasis, lipotoxicity and the metabolic syndrome. Biochim Biophys Acta 2010, 1801(3):209-214.

20. Jonas A, Phillips MC: Chapter 17 - Lipoprotein structure. In Biochemistry of Lipids, Lipoproteins and Membranes. 5th edition. Edited by Vance DE, Vance JE. UK: Elsevier; 2008.

21. Wettesten M, Bostrom K, Bondjers G, Jarfeldt M, Norfeldt PI, Carrella M, Wiklund O, Boren J, Olofsson SO: Pulse-chase studies of the synthesis of apolipoprotein B in a human hepatoma cell line, Hep G2. Eur J Biochem 1985, 149(3):461-466.

22. Dixon JL, Furukawa S, Ginsberg HN: Oleate stimulates secretion of apolipoprotein B-containing lipoproteins from Hep G2 cells by inhibiting early intracellular degradation of apolipoprotein B. J Biol Chem 1991, 266(8):5080-5086.

23. Wiggins D, Gibbons GF: The lipolysis/esterification cycle of hepatic triacylglycerol. Its role in the secretion of very-low-density lipoprotein and its response to hormones and sulphonylureas. Biochem J 1992, 284(Pt 2):457-462.

24. Welte MA, Cermelli S, Griner J, Viera A, Guo Y, Kim DH, Gindhart JG, Gross SP: Regulation of lipid-droplet transport by the perilipin homolog LSD2. Curr Biol 2005, 15(14):1266-1275.

25. Kuerschner $L$, Moessinger $C$, Thiele $C$ : Imaging of lipid biosynthesis: how a neutral lipid enters lipid droplets. Traffic 2008, 9(3):338-352.

26. Cheng J, Fujita A, Ohsaki Y, Suzuki M, Shinohara Y, Fujimoto T: Quantitative electron microscopy shows uniform incorporation of triglycerides into existing lipid droplets. Histochem Cell Biol 2009, 132(3):281-291.

27. Bostrom P, Rutberg M, Ericsson J, Holmdahl P, Andersson L, Frohman MA, Boren J, Olofsson SO: Cytosolic lipid droplets increase in size by microtubule-dependent complex formation. Arterioscler Thromb Vasc Biol 2005, 25(9):1945-1951. 
28. Gong J, Sun Z, Wu L, Xu W, Schieber N, Xu D, Shui G, Yang H, Parton RG, L P: Fsp27 promotes lipid droplet growth by lipid exchange and transfer at lipid droplet contact sites. J Cell Biol 2011, 195(6):953-963.

29. Ariotti N, Murphy S, Hamilton NA, Wu L, Green K, Schieber NL, Li P, Martin S, Parton RG: Postlipolytic insulin-dependent remodeling of micro lipid droplets in adipocytes. Mol Biol Cell 2012, 23(10):1826-1837.

30. Paar M, Jungst C, Steiner NA, Magnes C, Sinner F, Kolb D, Lass A, Zimmermann R, Zumbusch A, Kohlwein SD, Wolinski H: Remodeling of lipid droplets during lipolysis and growth in adipocytes. J Biol Chem 2012, 287(14):11164-11173.

31. Marcinkiewicz A, Gauthier D, Garcia A, Brasaemle DL: The phosphorylation of serine 492 of perilipin a directs lipid droplet fragmentation and dispersion. J Biol Chem 2006, 281(17):11901-11909.

32. Toh SY, Gong J, Du G, Li JZ, Yang S, Ye J, Yao H, Zhang Y, Xue B, Li Q, Yang H, Wen Z, Li P: Up-regulation of mitochondrial activity and acquirement of brown adipose tissue-like property in the white adipose tissue of fsp27 deficient mice. PLoS One 2008, 3(8):e2890.

33. Nishino N, Tamori Y, Tateya S, Kawaguchi T, Shibakusa T, Mizunoya W, Inoue K, Kitazawa R, Kitazawa S, Matsuki Y, Hiramatsu R, Masubuchi S, Omachi A, Kimura K, Saito M, Amo T, Ohta S, Yamaguchi T, Osumi T, Cheng J, Fujimoto T, Nakao H, Nakao K, Aiba A, Okamura H, Fushiki T, Kasuga M: FSP27 contributes to efficient energy storage in murine white adipocytes by promoting the formation of unilocular lipid droplets. J Clin Invest 2008, 118(8):2808-2821.

34. Jacobs RL, Zhao Y, Koonen DP, Sletten T, Su B, Lingrell S, Cao G, Peake DA, Kuo MS, Proctor SD, Kennedy BP, Dyck JR, Vance DE: Impaired de novo choline synthesis explains why phosphatidylethanolamine N-methyltransferasedeficient mice are protected from diet-induced obesity. J Biol Chem 2010, 285(29):22403-22413.

35. Kennedy EP, Weiss SB: The function of cytidine coenzymes in the biosynthesis of phospholipides. J Biol Chem 1956, 222(1):193-214.

36. Lands WE: Metabolism of glycerolipides; a comparison of lecithin and triglyceride synthesis. J Biol Chem 1958, 231(2):883-888.

37. Nakanishi H, Shindou H, Hishikawa D, Harayama T, Ogasawara R, Suwabe A, Taguchi R, Shimizu T: Cloning and characterization of mouse lung-type acyl-CoA:lysophosphatidylcholine acyltransferase 1 (LPCAT1). Expression in alveolar type II cells and possible involvement in surfactant production. J Biol Chem 2006, 281(29):20140-20147.

38. Chen X, Hyatt BA, Mucenski ML, Mason RJ, Shannon JM: Identification and characterization of a lysophosphatidylcholine acyltransferase in alveolar type II cells. Proc Natl Acad Sci U S A 2006, 103(31):11724-11729.

39. Shindou H, Hishikawa D, Nakanishi H, Harayama T, Ishii S, Taguchi R, Shimizu T: A single enzyme catalyzes both platelet-activating factor production and membrane biogenesis of inflammatory cells. Cloning and characterization of acetyl-CoA:LYSO-PAF acetyltransferase. J Biol Chem 2007, 282(9):6532-6539.

40. Soupene E, Fyrst H, Kuypers FA: Mammalian acyl-CoA:lysophosphatidylcholine acyltransferase enzymes. Proc Natl Acad Sci U S A 2008, 105(1):88-93.

41. Zhao Y, Chen Y, Bonacci TM, Bredt DS, Li S, Bensch WR, Moller DE, Kowala M, Konrad RJ, Cao G: Identification and characterization of a lysophosphatidylcholine acyltransferase that is primarily expressed in metabolic tissues. J Biol Chem 2008, 283(13):8258-8265.

42. Soupene E, Kuypers FA: Phosphatidylcholine formation by LPCAT1 is regulated by $\mathrm{Ca} 2+$ and the redox status of the cell. BMC Biochem 2012, 13(1):8.

43. Moessinger C, Kuerschner L, Spandl J, Shevchenko A, Thiele C: Human lysophosphatidylcholine acyltransferases 1 and 2 are located in lipid droplets where they catalyze the formation of phosphatidylcholine. J Biol Chem 2011, 286(24):21330-21339.

44. Ohsaki Y, Cheng J, Fujita A, Tokumoto T, Fujimoto T: Cytoplasmic lipid droplets are sites of convergence of proteasomal and autophagic degradation of apolipoprotein B. Mol Biol Cell 2006, 17(6):2674-2683.

45. Yao H, Ye J: Long chain acyl-CoA synthetase 3-mediated phosphatidylcholine synthesis is required for assembly of very low density lipoproteins in human hepatoma Huh7 cells. J Biol Chem 2008, 283(2):849-854.

46. Fujimoto $Y$, Itabe H, Kinoshita T, Homma KJ, Onoduka J, Mori M, Yamaguchi S, Makita M, Higashi Y, Yamashita A, Takano T: Involvement of ACSL in local synthesis of neutral lipids in cytoplasmic lipid droplets in human hepatocyte HuH7. J Lipid Res 2007, 48(6):1280-1292.

47. Guo Y, Walther TC, Rao M, Stuurman N, Goshima G, Terayama K, Wong JS, Vale RD, Walter P, Farese RV Jr: Functional genomic screen reveals genes involved in lipid-droplet formation and utilization. Nature 2008, 453 (7195):657-661.

48. Krahmer N, Guo Y, Wilfling F, Hilger M, Lingrell S, Heger K, Newman HW, SchmidtSupprian M, Vance DE, Mann M, Farese RV, Walther TC: Phosphatidylcholine synthesis for lipid droplet expansion is mediated by localized activation of CTP:phosphocholine cytidylyltransferase. Cell Metab 2011, 14(4):504-515.

49. Jackowski S, Wang J, Baburina I: Activity of the phosphatidylcholine biosynthetic pathway modulates the distribution of fatty acids into glycerolipids in proliferating cells. Biochim Biophys Acta 2000, 1483(3):301-315.

50. Cao J, Shan D, Revett T, Li D, Wu L, Liu W, Tobin JF, Gimeno RE: Molecular identification of a novel mammalian brain isoform of acyl-CoA:lysophospholipid acyltransferase with prominent ethanolamine lysophospholipid acylating activity, LPEAT2. J Biol Chem 2008, 283(27):19049-19057.

51. Teixeira L, Rabouille C, Rorth P, Ephrussi A, Vanzo NF: Drosophila Perilipin/ ADRP homologue Lsd2 regulates lipid metabolism. Mech Dev 2003, 120(9):1071-1081.

52. Gronke S, Mildner A, Fellert S, Tennagels N, Petry S, Muller G, Jackle H, Kuhnlein RP: Brummer lipase is an evolutionary conserved fat storage regulator in Drosophila. Cell Metab 2005, 1(5):323-330.

53. Arrese EL, Rivera L, Hamada M, Mirza S, Hartson SD, Weintraub S, Soulages JL: Function and structure of lipid storage droplet protein 1 studied in lipoprotein complexes. Arch Biochem Biophys 2008, 473(1):42-47.

54. Beller M, Bulankina AV, Hsiao HH, Urlaub H, Jackle $H$, Kuhnlein RP: PERILIPIN-dependent control of lipid droplet structure and fat storage in Drosophila. Cell Metab 2010, 12(5):521-532.

55. Fuss B, Becker T, Zinke I, Hoch M: The cytohesin Steppke is essential for insulin signalling in Drosophila. Nature 2006, 444(7121):945-948.

56. Bauer R, Voelzmann A, Breiden B, Schepers U, Farwanah H, Hahn I, Eckardt F, Sandhoff K, Hoch M: Schlank, a member of the ceramide synthase family controls growth and body fat in Drosophila. EMBO J 2009, 28 (23):3706-3716.

57. Becker T, Loch G, Beyer M, Zinke I, Aschenbrenner AC, Carrera P, Inhester T, Schultze JL, Hoch M: FOXO-dependent regulation of innate immune homeostasis. Nature 2010, 463(7279):369-373.

58. Arrese EL, Soulages JL: Insect fat body: energy, metabolism, and regulation. Annu Rev Entomol 2010, 55:207-225.

59. Cases S, Smith SJ, Zheng YW, Myers HM, Lear SR, Sande E, Novak S, Collins C, Welch CB, Lusis AJ, Erickson SK, Farese RV Jr: Identification of a gene encoding an acyl CoA:diacylglycerol acyltransferase, a key enzyme in triacylglycerol synthesis. Proc Natl Acad Sci U S A 1998, 95(22):13018-13023.

60. Stone SJ, Levin MC, Farese RV Jr: Membrane topology and identification of key functional amino acid residues of murine acyl-CoA:diacylglycerol acyltransferase-2. J Biol Chem 2006, 281(52):40273-40282.

61. Stone SJ, Levin MC, Zhou P, Han J, Walther TC, Farese RV Jr: The endoplasmic reticulum enzyme DGAT2 is found in mitochondria-associated membranes and has a mitochondrial targeting signal that promotes its association with mitochondria. J Biol Chem 2009, 284(8):5352-5361.

62. Henneberry AL, Wright MM, McMaster CR: The major sites of cellular phospholipid synthesis and molecular determinants of Fatty Acid and lipid head group specificity. Mol Biol Cell 2002, 13(9):3148-3161.

63. Hishikawa D, Shindou H, Kobayashi S, Nakanishi H, Taguchi R, Shimizu T: Discovery of a lysophospholipid acyltransferase family essential for membrane asymmetry and diversity. Proc Natl Acad Sci U S A 2008, 105 (8):2830-2835.

64. Bouchoux J, Beilstein F, Pauquai T, Guerrera IC, Chateau D, Ly N, Alqub M, Klein C, Chambaz J, Rousset M, Rousset M, Lacorte JM, Morel E, Demignot S: The proteome of cytosolic lipid droplets isolated from differentiated Caco-2/TC7 enterocytes reveals cell-specific characteristics. Biol Cell 2011, 103(11):499-517.

65. Butler PL, Mallampalli RK: Cross-talk between remodeling and de novo pathways maintains phospholipid balance through ubiquitination. J Biol Chem 2010, 285(9):6246-6258.

66. Li Z, Vance DE: Phosphatidylcholine and choline homeostasis. J Lipid Res 2008, 49(6):1187-1194.

67. Walker AK, Jacobs RL, Watts JL, Rottiers V, Jiang K, Finnegan DM, Shioda T, Hansen M, Yang F, Niebergall $\sqcup$, Vance DE, Tzoneva M, Hart AC, Näär AM: A conserved SREBP-1/phosphatidylcholine feedback circuit regulates lipogenesis in metazoans. Cell 2011, 147(4):840-852

68. Penno A, Hackenbroich G, Thiele C: Phospholipids and lipid droplets. Biochim Biophys Acta 2013, 1831(3):589-594. 
69. Ridgway ND: The role of phosphatidylcholine and choline metabolites to cell proliferation and survival. Crit Rev Biochem Mol Biol 2013, 48(1):20-38.

70. Fagone P, Jackowski S: Phosphatidylcholine and the CDP-choline cycle. Biochim Biophys Acta 2013, 1831(3):523-532.

71. Wang $H$, Gilham $D$, Lehner R: Proteomic and lipid characterization of apolipoprotein B-free luminal lipid droplets from mouse liver microsomes: implications for very low density lipoprotein assembly. J Biol Chem 2007, 282(45):33218-33226.

72. Kuhnlein RP: Lipid droplet-based storage fat metabolism in Drosophila: thematic review series: lipid droplet synthesis and metabolism: from yeast to man. J Lipid Res 2012, 53(8):1430-1436.

73. Spandl J, White DJ, Peychl J, Thiele C: Live cell multicolor imaging of lipid droplets with a new dye, LD540. Traffic 2009, 10(11):1579-1584.

74. Ejsing CS, Sampaio JL, Surendranath V, Duchoslav E, Ekroos K, Klemm RW, Simons K, Shevchenko A: Global analysis of the yeast lipidome by quantitative shotgun mass spectrometry. Proc Natl Acad Sci U S A 2009, 106(7):2136-2141.

75. Ejsing CS, Duchoslav E, Sampaio J, Simons K, Bonner R, Thiele C, Ekroos K, Shevchenko A: Automated identification and quantification of glycerophospholipid molecular species by multiple precursor ion scanning. Anal Chem 2006, 78(17):6202-6214.

76. Zech T, Ejsing CS, Gaus K, de Wet B, Shevchenko A, Simons K, Harder T: Accumulation of raft lipids in T-cell plasma membrane domains engaged in TCR signalling. EMBO J 2009, 28(5):466-476.

77. Schwudke D, Hannich JT, Surendranath V, Grimard V, Moehring T, Burton L, Kurzchalia T, Shevchenko A: Top-down lipidomic screens by multivariate analysis of high-resolution survey mass spectra. Anal Chem 2007, 79(11):4083-4093.

78. Gaebler A, Milan R, Straub L, Hoelper D, Kuerschner L, Thiele C: Alkyne lipids as substrates for click chemistry-based in vitro enzymatic assays. J Lipid Res 2013, 54(8):2282-2290.

79. Thiele C, Papan C, Hoelper D, Kusserow K, Gaebler A, Schoene M, Piotrowitz K, Lohmann D, Spandl J, Stevanovic A, Shevchenko A, Kuerschner L: Tracing fatty acid metabolism by click chemistry. ACS Chem Biol 2012, 7(12):2004-2011.

doi:10.1186/s12860-014-0043-3

Cite this article as: Moessinger et al:: Two different pathways of

phosphatidylcholine synthesis, the Kennedy Pathway and the Lands Cycle, differentially regulate cellular triacylglycerol storage. BMC Cell Biology 2014 15:43.

\section{Submit your next manuscript to BioMed Central and take full advantage of:}

- Convenient online submission

- Thorough peer review

- No space constraints or color figure charges

- Immediate publication on acceptance

- Inclusion in PubMed, CAS, Scopus and Google Scholar

- Research which is freely available for redistribution 